\title{
Detection of Tannerella forsythia from saliva samples in different ethnic majority groups in Sarawak
}

\author{
Elexson Nillian ${ }^{a^{*}}$, Grace Bebey ${ }^{a}$, Fatin Nabilah Ngua ${ }^{a}$ Nur Diyana ${ }^{a}$, Amirah Zakirah ${ }^{a}$ Eddy Bolia, \\ Melvin Chung Hsien Liang ${ }^{\mathrm{b}}$ \\ ${ }^{a}$ Faculty of Resource Science and Technology, University Malaysia Sarawak, 94300, Kota Samarahan, Sarawak, Malaysia \\ ${ }^{b}$ Faculty of Medicine and Health Sciences, University Malaysia Sarawak, 94300, Kota Samarahan, Sarawak, Malaysia
}

Received 12th September 2020 / Accepted 21st January 2021

\begin{abstract}
Nowadays racial and ethnic differences in health care has become a growing concern. It is one of the critical determinant in influencing the genotype of the host in which may results in some diseases such as periodontal disease. Tannerella forsythia can be found in oral cavity and have the strongest relation in resulting on the destruction of connective tissue in periodontal disease. This research is aim to investigate the prevalence of periodontal pathogens, particularly T. forsythia in four major ethnic groups in Sarawak which may result in periodontal disease in Sarawak. This disease may due to the results from the infection of the tissue supporting the teeth. A total of $(n=40)$ saliva samples consist of 10 samples for each ethnic groups such as Iban, Malay, Chinese and Bidayuh were collected in Kuching and Kota Samarahan using culture-independent method. The DNA was extracted from saliva based on Phenol Chloroform Isoamyl Alcohol method. After that, $16 \mathrm{~S}$ rRNA gene was then amplified via PCR for bacterial detection using $27 \mathrm{~F}$ and $1492 \mathrm{R}$ primers, followed by PG-F and PG-R primers set in identifying T. forsythia. The PCR product was observed on 1.5\% gel electrophoresis. As a result, the presence of bacteria $T$. forsythia was found more frequently from saliva samples of ethnic in Iban (70\%), followed by Malay (60\%), Bidayuh $(60 \%)$ and lastly Chinese (50\%). The differences of demographic, certain cultural beliefs and practices might affect the oral health status. This finding show that it may help to identify the risk groups and has contributed an additional evidence for the association between ethnicity and periodontal disease.
\end{abstract}

Keywords: T. forsythia, Sarawak Ethnic group, periodontal disease

\section{INTRODUCTION}

Approximately more than 1000 of bacteria species are present in the human body, in which some of it may promote health while the others may lead to certain disease ( $\mathrm{Li}$ et al., 2014). The oral cavity consists of a wide variety of oral microbiome which consist of over 700 different bacterial species. The component of these microbial populations in the community plays a crucial aspect in ecological balance (Aas et al., 2005). Bacterial DNA in saliva is important in the microbiological studies which can also act as an indicator in monitoring health and for disease diagnosis (Yoshizawa et al., 2013). However, increase in the number of the oral bacteria may also lead to human oral disease such as caries disease and periodontal disease (Paster et al., 2001; Dewhirst et al., 2010).

Periodontal disease has been recognized as the most common human infections (Camelo-Castillo et al., 2015). Nasruddin et al. (2014) stated that the

\footnotetext{
*Author for correspondence: Elexson Nillian, Faculty of Resource Science and Technology, Universiti Malaysia Sarawak, 94300 Kota Samarahan, Sarawak, Malaysia. Email - nelexson@.unimas.my
} 
overall currency in the population for periodontal disease has been found higher in Malaysia. Tannerella forsythia is known to be presented in person with periodontitis and sometimes in those without disease. However, it is the least understood microorganism among the three members of red complex (Wadhwani et al., 2013). In addition, an alternative way in determining the relationship of $T$. forsythia with periodontal health status has not yet been reported (Leys et al., 2002).

From previous studies, the prevalence of the subgingival periodontal pathogens had been shown to vary across different ethnic backgrounds and this may explain the relationship between ethnicity and the periodontal disease (Younis et al., 2012). Some diseases are likely to be more common in some ethnic groups. Different prevalence of periodontal pathogens including $T$. forsythia had been reported from different countries indicates a specific distribution patterns in ethnically distinct populations. From the reports on the oral health status in United states, although it has been suggested that poor oral health status may arise in the people from different ethnic minorities, certain cultural beliefs and practices might also affect their oral health status (Butani et al., 2008).

From previous studies, it had been suggested that the distribution of oral microbiome, especially on the proportion and prevalence of periodontal pathogen can be affected by the genetic as well as environmental factors (Siqueira et al., 2004). However, little information is available regarding the subgingival microbiota from different ethnic groups in Malaysia especially in Sarawak. According to Collins et al. (2016), only in recent years that the prevalence data of the periodontal pathogens has been determined in developing countries.

The major concern of this study is to extract the bacteria from saliva and identify the T. forsythia especially in the region that has a multi-ethnic population particularly in Sarawak. Therefore, by obtaining the information about the distribution of periodontal pathogens among the ethnic groups, it may help in identifying the risk groups and thus can promote the oral health care awareness or early periodontal therapy among the population.

The objectives of this study are to identify the presence of $T$. forsythia in DNA extracted from saliva via Polymerase Chain Reaction (PCR) and to compare the prevalence of $T$. forsythia in different major ethnic groups in Sarawak.

\section{MATERIALS AND METHODS}

\section{Sampling}

Ethical clearance for research was approved by medical ethics committee of Faculty of Medicine and Health Sciences UNIMAS under UNIMAS/NC.21.02/03.02 (72). In this study, saliva samples were collected from 40 healthy individual (range above 18 years old) from different ethnic groups in Kuching and Kota Samarahan area. Questionnaire and consent forms were given to the respondents. The samples were taken before breakfast. Individual subject was instructed to rinsed their mouth with tap water for 10 seconds. 30 minutes after rinsing, subject was required to split $2 \mathrm{ml}$ of saliva samples into a new tube. 40 samples was collected, where 10 of each samples ethnic groups (Iban, Malays, Chinese and Bidayuh). A survey had also been given during the sample collection. Once collected, all the samples were then kept in freezer at $-20^{\circ} \mathrm{C}$ before performing DNA extraction (Barker, 1998).

\section{DNA extraction}

All the samples were in a liquid state before performing DNA extraction. The PhenolChloroform-Isoamyl technique was used in this study. $2 \mathrm{ml}$ of lysis buffer (0.5 EDTA, $5 \mathrm{M} \mathrm{NaCl}$, $1 \mathrm{M}$ Tris, $\mathrm{pH} 8,10 \%$ SDS) were added to each of the saliva sample and mixed well. $100 \mu \mathrm{L}$ of the mixture was transferred into a micro centrifuge tube and then mixed with $10 \mu \mathrm{L}$ Proteinase $\mathrm{K}$ (Vivantis) for further tissue digestion. The mixture was incubated at $55^{\circ} \mathrm{C}$ until the mixture turned clear (Barker, 1998).

After incubation, equal volume of PhenolChloroform-Isoamyl (25:24:1) alcohol (Thermo Fisher) was added to the mixture and mixed gently for 5 minutes. The mixture then centrifuged for 10 minutes at $10000 \mathrm{rpm}$ at room temperature. The aqueous top was transferred to the new tube. This step was repeated for several times. Next, equal volume of Chloroform-Isoamyl (24:1) alcohol (Thermo Fisher Scientific) was added and 
mixed gently for 2 minutes. The solutions then centrifuged at $10000 \mathrm{rpm}$ for 1 minutes. Top aqueous was then removed to the new tube and added with 2-2.5 volume of ice-cold 100\% ethanol. The mixture was mixed gently and incubated in $-20^{\circ} \mathrm{C}$ for overnight (Barker, 1998).

The next day, the mixture was thawed and centrifuged at $10000 \mathrm{rpm}$ for 10 minutes. The supernatant was poured out and the pellet formed was washed with $70 \%$ ethanol. The solution was centrifuged again for 10 minutes at $10000 \mathrm{rpm}$. The supernatant was pour out from the tube and allowed the pellet to air-dry. Lastly, $50 \mu \mathrm{L}$ of $\mathrm{ddH}_{2} \mathrm{O}$ was added in order to resuspend the pellet. The sample was then kept in $-20^{\circ} \mathrm{C}$ for PCR used (Barker, 1998).

\section{Polymerase Chain Reaction (PCR)}

DNA extracted from the sample will be subjected to PCR analysis. For PCR reagent, $2.5 \mu \mathrm{L}$ of Easy Taq Buffer (Transgene), $1.5 \mu \mathrm{L}$ of $\mathrm{MgCl}_{2}$ (Thermo Fisher Scientific), $2.5 \mu \mathrm{L}$ of dNTP (Transgene), $1.0 \mu \mathrm{L}$ for both forward primer and reverse primer and $0.2 \mu \mathrm{L}$ of Easy Taq DNA polymerase (Transgene) is used per reaction. Negative controls was included in both PCR assay where it contain the sterile ultrapure water, while positive control (T. forsythia ATCC 43037) was include in PCR amplification in which it comprised of genomic DNA that is extracted from the bacterial species (Siqueira et al., 2004).

PCR assay was performed separately for $16 \mathrm{~S}$ rRNA genes and Tannerella forsythia. Universal primers such as 27F (5'-AGA GTT TGA TCC TGG CTC AG-3') and 1492R (5'-ACG GCT ACC T'TG T'TA CGA CT'T-3') were used for $16 \mathrm{~S}$ rRNA while T. forsythia was detected using specific primers including TF-F (5'-GCG TAT GTA ACC TGC CCG CA-3') and TF-R (5'-TCG TTC AGT GTC AGT TAT ACC T-3'). All PCRs were performed in an Eppendorf Master Cycle Personal apparatus. The first reaction for $16 \mathrm{~S}$ include an initial denaturation at $95^{\circ} \mathrm{C}$ for 10 minutes, followed by 26 cycles of denaturation at $94^{\circ} \mathrm{C}$ (30 seconds), annealing at $55^{\circ} \mathrm{C}(1$ minute) and extension at $72^{\circ} \mathrm{C}$ ( 1 minute 30 seconds), and a final $72^{\circ} \mathrm{C}$ extension step for 10 minutes. For the second reaction of amplification specific for $T$. forsythia comprised an initial denaturation at $95^{\circ} \mathrm{C}$
T. forsythia for 2 minutes, followed by 35 cycles of denaturation at $94^{\circ} \mathrm{C}$ (30 seconds), annealing at $56^{\circ} \mathrm{C}$ (1 minutes), extension at $72^{\circ} \mathrm{C}$ ( 1 minute) and final extension step at $72^{\circ} \mathrm{C}(10$ minutes).

For the detection and confirmation of final PCR products, the amplification product mixture was subjected to electrophoresis through 1.5\% agarose gel (BioRad Laboratories). Amplified DNA fragments were visualized by UV fluorescence after being stained with ethidium bromide. Positive reactions were determine based on the appearance of clearly visible bands of expected length.

\section{RESULTS}

\section{$16 S \boldsymbol{r R N A}$ gene amplification}

PCR amplification of 16S rRNA gene using universal primers resulted in a single band of predicted size. Agarose gel electrophoresis analysis showed that out of 40 samples which were amplified for 16S rRNA gene, all samples showed the positive result with a presence of a clear band with an amplicon size of $1500 \mathrm{bp}$. The result for the amplification of $16 \mathrm{~S}$ gene in each ethnic groups are shown in Figure 1. All positive samples were then used for next PCR amplification for the of T. forsythia.

\section{Tannerella forsythia amplification}

The samples that were positive for Tannerella forsythia showed only one single band of expected amplicon size (641bp) (Figure 2(A)). Using specific primers, the results showing the detection of T. forsythia are shown in Figure $2(\mathrm{~B}-\mathrm{E})$. No T. forsythia-specific amplicons were observed in negative controls. Comparison of the detection of T. forsythia in four ethnic groups revealed that the bacteria was more detected in Iban group samples than the others, for an overall frequency of $70 \%$ (Figure 2 (B)). However, Chinese group showed the lowest detection of $T$. forsythia with frequency of $50 \%$ (Figure 2 (D)). On the other hand, both Malay and Bidayuh groups showed the same results where $60 \%$ of the samples were positive for the detection of T. Forsythia as in Figure 3. 


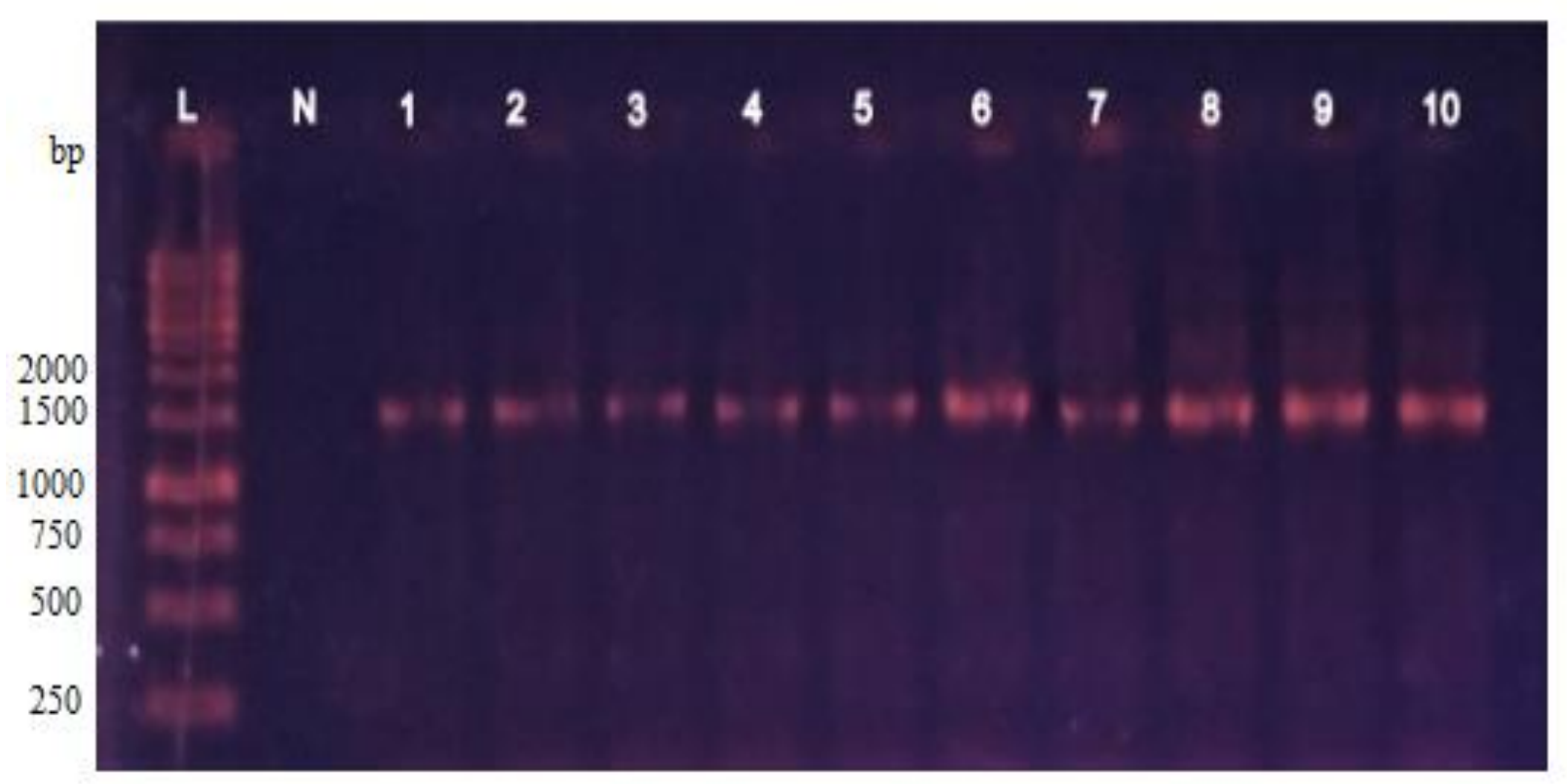

Figure 1. PCR product of 16S rRNA gene. Lane L: $1 \mathrm{~kb}$ DNA ladder; Lane N: Distilled water (negative control); Lanes 1-10: saliva samples.

\section{DISCUSSION}

\section{Amplification of $16 S \mathrm{rRNA}$ gene}

In recent years, previous study had shown that PCR-based technique is an excellent tool for identifying periodontal bacteria from subgingival samples. It is an accurate, rapid and accurate technique for the identification, detection as well as quantification of the periodontal pathogens (Valones et al., 2009; Rajendran et al., 2016).

The presence of a clear band of the expected size is indicate as a positive result. In the first round of PCR, 16S rRNA gene was detected in all 40 samples for four major ethnic groups as a control to verify the presence of bacterial DNA in the saliva samples. These results indicate the absence of inhibitors in the reaction during the amplification and demonstrate that the bacterial DNA are suitable to be further used for PCR analysis (Siqueira et al., 2004). All positive 16S rRNA gene samples were then used to detect the presence of T. forsythia.

\section{Detection of Tannerella forsythia}

The result of this study in Figure 3, demonstrate the prevalence of $T$. forsythia in different ethnic groups such as Iban, Malay, Chinese and Bidayuh. T. forsythia was one of the bacteria that can be detected in majority of the subjects before the emergence of periodontal treatment (Ready et al., 2008). However, they were hardly being mentioned in previous studies (Gomes et al., 2007). Victor et al., (2008) reported that PCR is an easy-to-perform technique in order to detect the periodontal pathogens, including T. forsythia in subgingival samples. Also, saliva had been reported to have a great diagnostic value in identify $T$. forsythia and other subgingival sample (Kononen et al., 2007).

From previous studies, T. forsythia and other two members of "red complex" can also be observed in healthy individuals or minimal periodontal disease where it may indicate these individuals as carriers and are at risk of developing the periodontal disease (Bik et al., 2010; Younis et al., 2012). According to some previous studies, individual with single pathogen had higher potency to have severe disease than those with two or more pathogens, which indicate that both positive and negative bacterial interactions were crucial in resulting in periodontal disease (Paju et al., 2009). Even though the high risk in periodontal disease is directly associated with both the presence and amount of bacterial species, the genetic variability of host may also affect the individual susceptibility to the development of disease (da-Silva et al., 2017). 

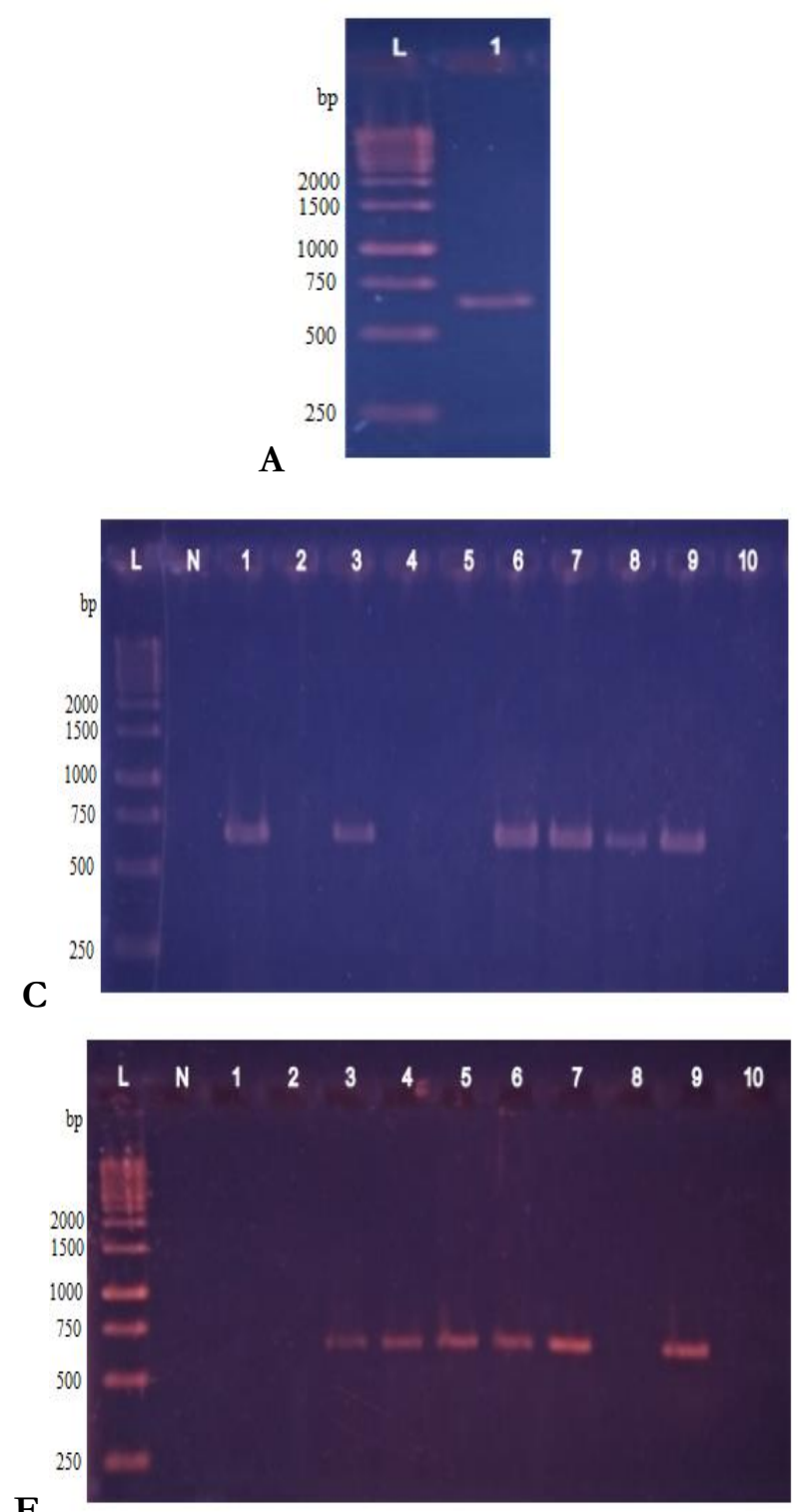

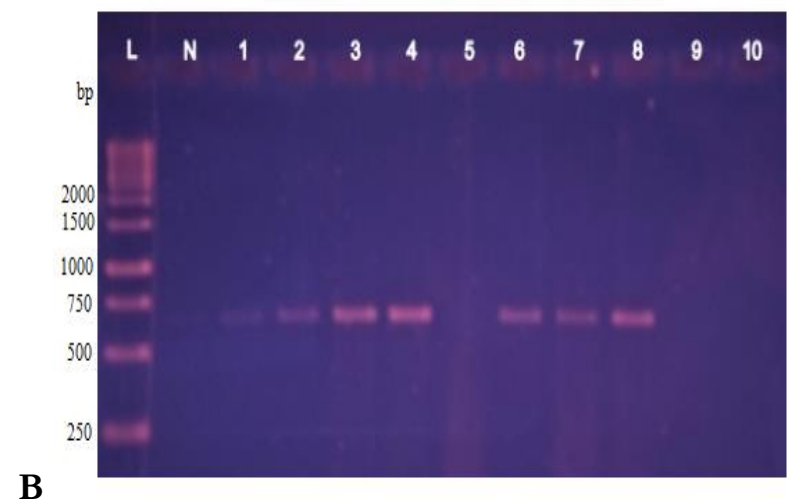

B

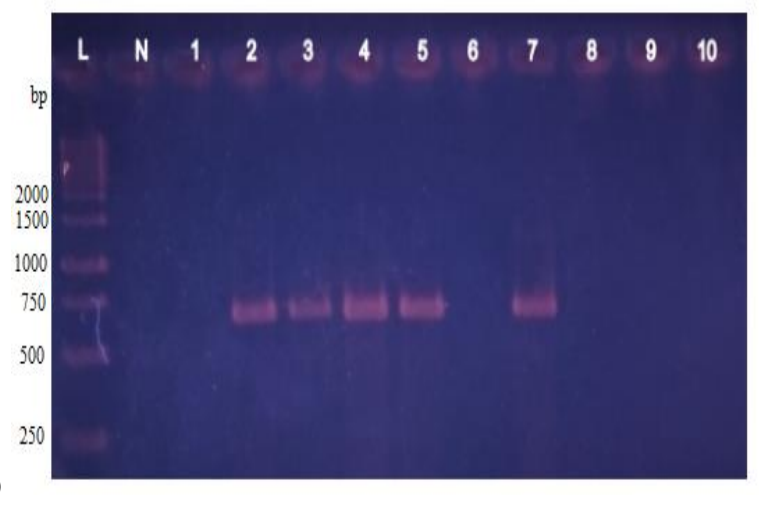

Figure 2. Positive amplification of T. forsythia in four major ethnic groups. (A) Positive control of T. forsythia ATCC 43037 (B) Iban ethnic group (C) Malay ethnic group (D) Chinese ethnic group (E) Bidayuh ethnic group

Percentage on the Pre-assumption of prevalence of T. forsythia

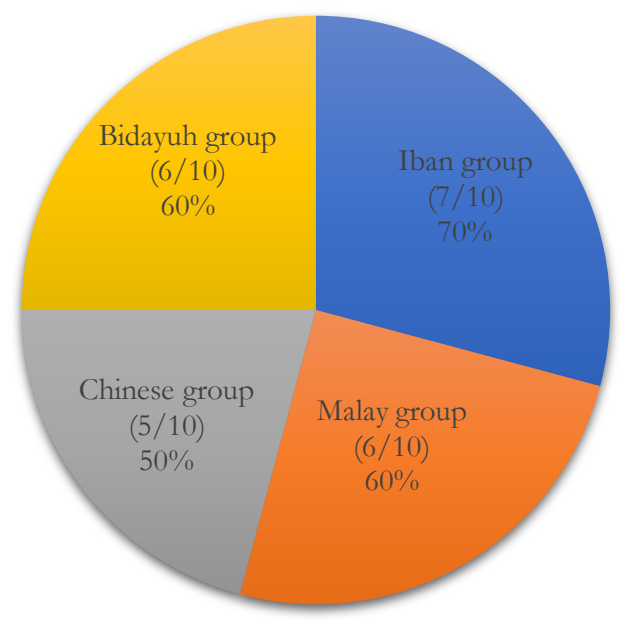

- Iban group

- Malay group

- Chinese group

- Bidayuh group

Figure 3. Percentage on the pre-assumption of prevalence of T. forsythia detection 
From the result, the differences in the prevalence of $T$. forsythia among four different major ethnic groups were observed in this study. This may demonstrate that the prevalence of T. forsythia are closely linked to ethnicity with different religious practice, lifestyle, diet and socioeconomic among these ethnic groups. According to Tickle (2013), the research that associated with ethnicity and oral bacteria colonization had indicated that oral cavity may contain microbial signatures that can be differentiate between ethnicity and act as an individual fingerprint. From recent study, it had also been reported that ethnicity may affect the oral microbiome genetically (Mason et al., 2013). The variation in occurrence, extension and intensity of destruction by periodontal pathogens in individual level may also be explained by genetic variation (Costa et al., 2008).

Moreover, it is possible that ethnicity plays a role in bacterial selection as it is known that tooth and root morphologies varied across different ethnic group and this may define the environment for the colonization of bacteria (Lavelle, 1970; Mason et al., 2013). On top of that, each ethnic group also different in a broad range of nutritional, behavioral, social, residential, psychological and many other variables. Since biology can be adaptive to the environment conditions which the organisms exist, the interactions between social environment with innate and acquired biological factors are likely to be happen (William and Sternthal, 2010).

Nevertheless, little information is available regarding the microbiota distribution especially in Sarawak. In the present study, PCR was used to determine the prevalence of $T$. forsythia in subgingival microbiota from 40 subjects. Primers that were highly sensitive and specific for the bacterial species were used, where it enables precise identification of the known microbial species (Baumgartner et al., 2004). From the result, there was differences in the prevalence of $T$. forsytbia among different ethnic groups in Sarawak, in which Iban group has the highest frequency, followed by Malay and Bidayuh and relatively lower in Chinese. Thus, further investigation is required to identify the exact reason cause the clinical of the finding has not yet been determined.

In view of difficulty in recruiting these samples, smokers were not excluded, which may have been a potential cause of confounding bias (Vaithilingam et al., 2010). According to Farias et al., (2012), factor such as the involvement of smokers and non-smokers without distinguishing between the two and those with tooth loss or systemic disease may lead to samples selection bias. Therefore it might affect the distribution of periodontal pathogens and eventually influence the data. Comparison with other studies are hardly possible due to the lack of similar studies (Lom et al., 2016). Besides that, it is difficult to compare the prevalence of oral microbiota in different country as it had been reported that some of the prevalent species may varied across different country. This may due to the differences in racial, geographical, environmental, genetic, habitrelated behavior and many other factors (Virginia et al., 2015).

According to Siti et al. (2015), lifestyle such as smoking and alcohol habits, chronic disease such as diabetes, as well as genetic factors are known to be the risk factor of periodontal disease. Poor oral hygiene including rinsing, brushing, flossing and the regular dental care may also associated with prevalence of the disease (Perrone, 2013). It had been known that smoking is the well-established factor that highly associated with the prevalence of T. forsythia (Van-Dyke and Dave, 2005; Nagelberg, 2010; AlJehani, 2014). Notably, these aspect may shows the consistency of the results.

In this study, the high percentage of prevalence may due to smoking and alcohol drinking habit that highlights the possibility for the infection of T. forsythia to occur (Kubota et al., 2011). Similar results from previous studies showed that the counts of $T$. forsythia were observed higher in smokers (Ardilaet al., 2014; Sabanci and Eltas, 2018). In drinking habit, it had been shown that alcohol consumption was not one of the biggest risk factor for the prevalence of T. forsythia, although it may also lead to periodontal disease (AlJehani 2014; Lages et al., 2015). Alcohol and tobacco most potentially cause mouth and throat cancer risk, thus, persons who are heavy smokers and drinkers are 50 times more likely to get oral cancer compared to those who never smoke or drink heavily (Sabanci and Eltas, 2018).

The negative results of PCR products may be due to the presence of inhibitory substances in the plaque samples which inhibit the PCR reaction 
(Siqueira and Rocas, 2005). In addition, it could be caused by the contamination of samples or the PCR reagents. Error may also arise during sampling or the extraction of the saliva samples (Praveen et al., 2014). Failure to detect a band in PCR interpreted as the bacteria being either absent or present in small number. However, there were also some limitations in this study for such the samples data were too small to differentiate the differences of $T$. forsythia among the ethnic groups. Due to the limited number of samples in this study, it is hard to compare the ethnic differences in the prevalence of T. forsythia. Furthermore, although it was assumed that ethnicity is the main cause for the different percentage of $T$. forsythia in all four major ethnic groups, but this research did not assess more on social, economic or other factors related to their living habits that may partly explain the pronounced differences in T. forsythia prevalence that were observed in this study.

\section{CONCLUSION}

To summarize, the presence of T. Forsythia have been successfully identified in saliva from all four ethnic groups as they show successful amplification on agarose gel electrophoresis. It also indicated that such species are more likely to be detected in Iban ethnic group (70\%), followed by Malay $(60 \%)$ and Bidayuh $(60 \%)$ and lastly Chinese $(50 \%)$. This finding has provide additional evidence for the potential association between periodontal disease and ethnicity and useful in identification of the risk groups. However, the mere number of T. forsythia detected did not imply that other ethnic groups may have lower potency on periodontal disease, and therefore, further studies are recommended on expanding the samples data and reconsider the other factors that may be related to the ethnicity.

\section{ACKNOWLEDGEMENTS}

The authors would like to thank the MoHE Malaysia, UNIMAS and UPM. Research fund was sponsored by F07/SpMYRA/1712/2018 and
Research Acculturation Grant Scheme (RAGS)/RAGS/ ST01(1)/1314/2015(08) and Universiti Malaysia Sarawak (Unimas) Kota Samarahan, Kuching Sarawak.

\section{REFERENCES}

Aas, J. A., Paster, B. J., Stokes, L. N., Olsen, I. \& Dewhirst, F. E. 2005. Defining the normal bacterial flora of the oral cavity. Journal of Clinical Microbiology 43(11): 5721-5732.

AlJehani, Y. A. 2014. Risk factors of periodontal disease: Review of the literature. International Journal of Dentistry: 1-9.

Ardila, M. C. M., Ariza, G. A. A. \& Guzman, Z. I. C. 2014. Coexistence of Porphyromonasgingivalis, Tannerella forsythia and Treponemadenticola in the red bacterial complex in chronic periodontitis. International Journal of Odontostomatology 8(3): 359-364.

Barker, K. 2014. Phenol-Chloroform Isoamyl Alcohol (PCI) DNA Extraction. 1998. [cited 2019 30/4/2019]. Available from: http://hosted.usf.edu/ecoimmunology/wpcontent/uploads/2014/07/PCI-extraction.pdf.

Baumgartner, J. C., Siqueira, J. F., Xia, T. \& Rocas, I. N. 2004. Geographical differences in bacteria detected in endodontic infections using polymerase chain reaction. Journal of Endodontics 30(3): 141-144.

Bik, E. M, Long, C. D., Armitage, G. C., Loomer, P., Emerson, J. \& Mongodin, E. F. 2010. Bacterial diversity in the oral cavity of ten healthy individuals. The ISME Journal 4(8): 962 974.

Butani, Y, Weintraub, J. A. \& Barker, J. C. 2008. Oral health-related cultural beliefs for four racial/ethnic groups: Assessment of the literature. BMC Oral Health 8(26): 1-13.

Camelo-Castillo, A. J., Mira, A., Pico, A., Nibali, L., Henderson, B. \& Donos, N. 2015. Subgingival microbiota in health compared to periodontitis and the influence of smoking. Frontiers in Microbiology 6(119): 1-12.

Collins, J. R., Arredondo , A., Roa, A., Valdez, Y., Leon, R. \& Blanc, V. 2016. Periodontal pathogens and tetracycline resistance genes in subgingival biofilm of periodontally healthy and diseased Dominican adults. Clinical Oral Investigations 20: 349-356.

Costa, J. E., Gomes, C. C., Cota, L. M., Pataro, A. L., Silva, J. C. \& Gomez, R. S. 2008. Polymorphism in the promoter region of the gene for 5-HTT in individuals with aggressive periodontitis. Journal of Oral Science 50(2): 193-198.

Cruz-Flores, S., Rabinstein, A., Biller, J., Elkind, M .S. V, Griffith, P. \& Gorelick, P. B. 2011. Racial-ethnic disparities in stroke care: The American Experience. [cited 2019 30/4/2019]. Available from: https://www.ahajournals.org/doi/pdf/ 10.1161/STR.0b013e3182213e24.

Da-Silva, M. K., de-Carvalho, A. C. G., Alves, E. H. P., da-Silva L. D. S. \& Vasconcelos, D. F. P. 2017. Genetic factors and the risk of periodontitis development: findings from a systemic review composed of 13 studies of meta-analysis with 71,531 participants. International Journal of Dentistry: 1-9.

Department of Statistics Malaysia Official Website. Sarawak. 2019. [cited 2019 4/5/2019]. Available from: https://www.dosm.gov.my/v1/index.php?r=column/con e\&menu_id=clJnWTlTbWFHdmUwbmtSTE1EQStFZz0 9.

Dewhirst, F. E., Chen, T., Izard, J., Paster, B. J., Tanner, A. C. R. \& Yu,W. H. 2010. The human oral microbiome. Journal of Bacteriology 192(19): 5002-5017. 
Farias, B. C, Souzam, P. R. E., Ferreira, B., Melo, R. S. A., Machado, F. B. \& Gusmao, E.S. 2012. Occurrence of periodontal pathogens among patients with chronic periodontitis. Brazilian Journal of Microbiology 43(3): 909-916.

Gomes, B., Montagner, F., Jacinto, R., Zaia, A., Ferraz, C. \& Souzafilho, F. 2007. Polymerase chain reaction of Porphyromonasgingivalis, Treponemadenticola, and Tannerella forsythia in primary endodontic infections. Journal of Endodontics 33(9): 1049-1052.

Kononen, E., Paju, S., Pussinen, P. J., Hyvonen, M., Tella, P. D. \& Suominen-Taipale, L. 2007. Population-based study of salivary carriage of periodontal pathogens in adults. Journal of Clinical Microbiology 45(8): 2446-2451.

Kubota, M., Mariko ,T., Yamada, S., Okuda, K. \& Ishihara, K. 2011. Effect of smoking on subgingival microflora of patients with periodontitis in Japan. BMC Oral Health 1(1): 1-6.

Lages, E. J. P., Costa, F. O., Cortelli, S. C., Cortelli, J. R., Cota, L. O. M. \& Cyrino, R. M. 2015. Alcohol consumption and periodontitis: quantification of periodontal pathogens and cytokines. Journal of Periodontology 86(9): 1058-1068.

Lavelle, C. L. B. 1970. Crowding and spacing within the human dental arch of different racial groups. Archives of Oral Biology. 15(11): 1101-1103.

Leys, E. J., Lyons, S. R., Moeschberger, M. L., Rumpf, R. W. \& Griffen, A. L. 2002. Association of Bacteroides forsythus and a novel Bacteroidesphylotype with periodontitis. Journal of Clinical Microbiology 40(3): 821-825.

Li, J., Quinque, D., Horz, H. P., Li, M., Rzhetskaya, M. \& Raff, J. A, 2014. Comparative analysis of the human saliva microbiome from different climate zones: Alaska, Germany, and Africa. BMC Microbiology 14(316): 1-13.

Lom, F. Y., Uma, S., Renukanth, R. \& Chua, S. L. 2016. Prevalence of aggressive periodontitis in newly referred patients in a periodontal specialist government clinic. Malaysian Dental Journal 39(1): 9-25.

Mason, M. R., Nagaraja, H. N., Camerlengo, T., Joshi, V. \& Purnima, S. K. 2013. Deep sequencing identifies ethnicityspecific bacterial signatures in the oral microbiome. PLOSOne 8(10): 1-7.

Minority Rights Group International. Indigenous peoples and ethnic minorities in Sarawak. 2018. [cited 2019 4/5/2019]. Available from: https://minorityrights.org/minorities/ indigenous-peoples-and-ethnic-minorities-in-sarawak/

Nagelberg, R. H. 2010. Risk factors for periodontal disease. 2010. [cited 2019 30/4/2019]. Available from: https://www.dentaleconomics.com/articles/print/volume -100/issue-1/columns/gp-perio-the-oral-systemicconnection/risk-factors-for-periodontal-disease.html.

Nasruddin, J., Hina, H., Nor Azlida, M. N., Asma, M., Roslan, S. \& Rashidah, E. 2014. Is the burden of oral diseases higher in urban disadvantaged community compared to the national prevalence. BMC Public Health 14(3): 1-7.

Paju, S., Pussinen, P. J., Suominen-Taipale, L., Hyvonen, M., Knuuttila, M. \& Kononen, E. 2009. Detection of multiple pathogenic species in saliva is associated with periodontal infection in adults. Journal of Clinical Microbiology 47(1): 235238.

Paster, B. J., Boches, S. K., Galvin, J. L., Ericson, R. E. \& Lau, C. N. 2001. Bacterial diversity in human subgingival plaque. Journal of Bacteriology 183(12): 3770-3783.

Perrone, M. 2013. Periodontal Disease Risk Factors. 2013. [cited 2019 30/4/2019]. Available from: http://drperrone.com/ blog/periodontal-disease-risk-factors/.

Praveen, K. B., Aarati, N., Rashmi, B., Reshma, N. \& Nami, R. 2014. Comparisan of culture and polymerase chain reaction techniques in the identification of Tannerella forsythia in periodontal health and disease, an in vitro study. Journal of Indian Society Periodontology 18(2): 155-160.

Rajendran, M., Jaishree ,T. K. \& Nallasivam, L. 2016. Polymerase chain reaction: a molecular diagnostic tool in periodontology. Journal of Indian Society of Periodontology 20(2): 128-135.

Ready, D., D’Aiuto, F., Spratt ,D.A., Suvan, J., Tonetti ,M. S. \& Wilson, M. 2008. Disease severity associated with presence in subgingival plaque of Porphyromonasgingivalis, Aggregatibacter actinomycetemcomitans, and Tannerella forsythia, singly or in combination, as detected by nested multiplex PCR. Journal of Clinical Microbiology 46(10): 3380-3383.

Sabanci, A., Eltas, A. 2018. Comparison of periodontal and periimplant microflora in smokers. Juniper Online Journal of Case Studies 9(1): 1-4.

Siqueira, J. F., Jung, I., Rocas, I. N., Lee, C. \& de Janeiro, R. 2004. Differences in prevalence of the selected bacterial species in primary endodontic infections from two distinct geographic locations. Oral Surgery, Oral Medicine, Oral Pathology, Oral Radiology, and Endodontics (99): 641-647.

Siqueira, J. F., Rocas, I. N. 2005. Exploiting molecular methods to explore endodontic infections: Part 1 - Current molecular technologies for microbiological diagnosis. Journal of Endodontics 31(6): 411-423.

Siti, N. S., Azelinda, A., Haslina, T. \& Wan, M. W. M. 2015. Hypertension and its association with the severity of chronic periodontitis: a preliminary study. Archives of Orofacial Sciences 10(1): 3-9.

Tickle, M. 2013. Bacterial signatures create oral fingerprint. British Dental Journal 215(10): 492.

Vaithilingam, R. D., Taiyeb-Ali, T. B. \& Yusuf, R. 2010. Aggregatibacter actinomycetemcomitans and Prevotella intermedia in advanced chronic periodontitis patients. The Annals of Dentistry University of Malaya 17:1-8.

Valones, M. A. A, Guimaraes, R. L., Brandao L. A. C., de-Souza, P. R. E, Carvalho, A. A,. Crovela, S. 2009. Principles and applications of polymerase chain reaction in medical diagnostic fields: a review. Brazilian Journal of Microbiology 40: $1-11$.

Van-Dyke, T. E., Dave, S. 2005. Risk factors for periodontitis. Journal of the International Academy of Periodontology 7(1): 3-7.

Victor, L. V., Cortelli, S. C., Acquino, D. R,. Filho, J. D. \& Cortelli, J. R. 2008. Periodontal profile and presence of periodontal pathogens in young African-Americans from Salvador, Ba, Brazil. Brazilian Journal of Microbiology 39(2): 226-232.

Virginia, P., Carolina, V., Lourdes, Z., Alicia, B., Claudia, C. \& Luis, B. 2015. Detection and prevalence of periodontal pathogens in a Uruguayan population with chronic periodontitis using conventional methodology and metagenomics. Odontoestomatologia 25: 23-33.

Wadhwani, R. B., Chaudhary, M. S., Tharani, D. A. \& Chandak ,S. A. 2013. Effect of scaling and root planning on detection of Tannerella forsythia in chronic periodontitis. Journal of Oral Diseases 2013: 1-6.

William, D. R., Sternthal, M. 2010. Understanding racial/ethnic disparities in health: sociological contributions. Journal of Health and Social Behavior 51: 15-27.

Yoshizawa, J. M., Schafer, C. A., Schafer, J. J., Farrell, J. J., Paster, B. J. \& Wong, D. T, W. 2013. Salivary biomarkers: toward future clinical and diagnostic utilities. Clinical Microbiology Reviews 26(4): 781-791.

Younis, L. T., Tara, B. A. \& Rohana, Y. 2012. Periodontal status in relation to the pathogens Porphyromonas gingivalis and Tannerella forsythensis in the three main ethnic groups in Malaysia. European International Journal of Science and Technology 1(3): 97-105. 